\title{
DC TO DC CONVERTERS AND ITS APPLICATION FOR RAILWAY SYSTEM- A REVIEW
}

\author{
Sachin Kale \\ PG Student, Department of Electrical Engineering, \\ Government College of Engineering Aurangabad, Maharashtra, India \\ Dr. N.R. Bhasme \\ Associate Professor, Department of Electrical Engineering, \\ Government College of Engineering Aurangabad, Maharashtra, India
}

\begin{abstract}
In modern technologically advanced world, power electronic based converters are extensively used. Among them DC to DC converters are majorly used in transportation system because of its increased efficiency and regenerative system. The railway traction system is eco-friendly, pollution free and largely used transportation system in the world. A review of different types of DC-DC converter, isolated, nonisolated and its recent application in railway traction system is presented here. This paper also covers its key features such as high voltage conversion ratio, ripple factor, galvanic isolation and efficiency performance of DC to DC converters.
\end{abstract}

Keywords: Buck converter, Boost converter, Cuk converter, buck-boost converter, SEPIC converter, Flyback converter

Cite this Article: Sachin Kale and Dr. N.R. Bhasme, DC to DC Converters and its Application for Railway System- A Review, International Journal of Electrical Engineering \& Technology, 10(4), 2019, pp. 13-21.

http://iaeme.com/Home/issue/IJEET?Volume=10\&Issue $=4$

\section{INTRODUCTION}

In the early days of the railway invention, it is used to run on the coal. As technology developed with time new railway engines are developed which runs on petroleum oil such as petrol, diesel, etc. Now due to the increase in pollution and depleting sources of petroleum oil, there is a need of new invention in railway engines which will run on renewable energy along with electrical supply. The use of electricity for powering railway (locomotive) is known as the electric locomotive. In this electric locomotive system, railway engines are provided electricity from overhead lines. There are two types of electric locomotives, fully electrified locomotive system and hybrid locomotive system. In fully electrified locomotive system railway engines are totally dependent on power supply provided from overhead lines. This system does not have any backup supply in case of failure of electric lines. The hybrid system 
has little advantage in this case, as it is provided with the electric system and on-board prime movers which can be powered by diesel engine or gas turbines. In this system, electric supply acts as a primary source whereas other source acts as a backup supply. When railways running on the electricity, are superior in efficiency, speed, and become compact in size. Considering a fore mentioned advantages, the electrification of railway circuit increasing rapidly. While carrying out electrification of the railway line, we can either use an AC or DC system depending on the availability of supply[1]. AC electrification system again has two types, single phase AC and three phase AC. In the case of the DC system, $600 \mathrm{~V}$ to $700 \mathrm{~V}$ for tramways and sub-urban services are used. Tramways are a kind of locomotive system which runs on track which receives power from the overhead line throughout the city. Since it is the DC system, the best motor that can be used is DC series motor. This motor is best suitable because of its higher starting torque and speed is varied by changing firing angle of DC to DC converter and also best suited for frequent operation. DC equipments require for this system are lightweight and less costly. One of the greatest advantage of DC system in traction or transmission of power is that it causes no interference with telecommunication lines. Single phase AC system also called an AC low-frequency system using $15 \mathrm{kV}$ to $25 \mathrm{kV}$ at $16.7 \mathrm{~Hz}$ or $25 \mathrm{~Hz}$ supply. Electrical power from a generating station is transmitted to grid substation using three phase distribution system. At the grid substation, the transformer lowers the voltage to $25 \mathrm{kV}$ with $50 \mathrm{~Hz}$ frequency supply which is given to railway feeder. AC series motor is used and generally this system used for mainline services. Because of using Lowfrequency supply commutation, power factor, efficiency improves in $\mathrm{AC}$ motors and also reduces interference with other lines. In three phases AC system has induction motor operating at $3 \mathrm{kV}$ at $16.7 \mathrm{~Hz}$. This system employs two overhead lines and track rail form another phase but this raises many problems at crossing and junction. This system is suitable where power requirement is high and regeneration on large scale is possible likely in hilly areas. Also, 3 phase motor rating is 105 times greater than that of a single phase motor. Hence it can deliver more power and during regeneration, higher power can also be recovered. Induction motor is simple and robust with auto regeneration ability when driven simply above synchronous speed. Nowadays this system becomes very popular due to several benefits such as AC generation that can easily step up or down using a transformer, requirement of substations are less and light overhead lines that transfer power at high voltage and lower current.[1]

In all above railway traction systems, DC-DC converters play crucial role regarding operation and control. It uses semiconductor devices such as MOSFET, IGBT, etc to convert fixed DC into variable DC. These types of DC to DC converters have high power handling capacities with bidirectional power flow. In DC driven traction system, this converter matches the supply voltage, control speed and bidirectional power flow between supply and motor. In recent, these converters largely used for battery charging, discharging and electrical traction system. The hybrid traction system uses both electrical drive system and battery system. Compared to all converters, when electrical drives fails, the DC to DC with bidirectional flow will lead to safe operation, Because of these features of such converters have got unique and leading place in recent periods.. DC to DC converters are categorized in different types depending upon its rating which are discussed below.[2]

\section{TYPES OF DC TO DC CONVERTER}

\subsection{Buck Converter}

This converter is also known as step down converter which converts the higher voltage of input side to lower voltage at output side as shown in fig1. It operates in two modes depending on switch $\mathrm{ON}$ and $\mathrm{OFF}$ 


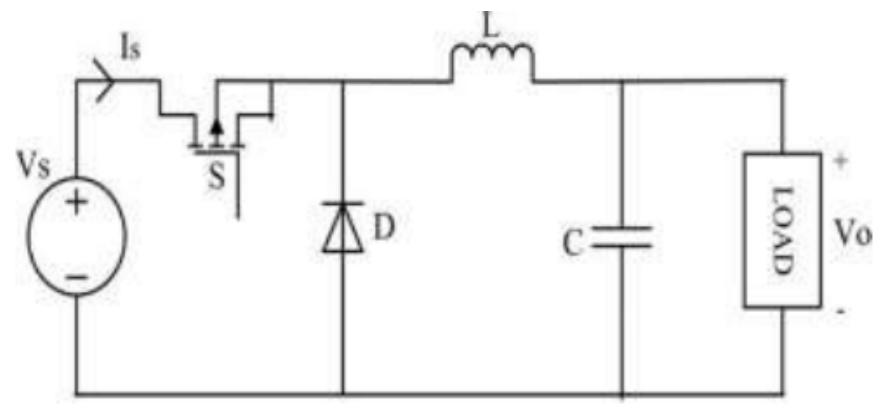

Figure 1 Buck Converter

This circuit includes voltage source Vs, diode D inductor L, filter capacitor C, switch S and load. Switch S is turned ON, the supply voltage Vs supplies current through the inductor, load and back to supply voltage Vs and supply voltage Vs appear across the output side and inductor starts charging. The diode is OFF condition in this case. When switch is in OFF position the inductor discharges and current flowing through the inductor, load and diode. It has the ability to provide minimum output ripple current and high input ripple current.[3,4] The output equation of this converter is given by

$$
V 0=\alpha V s
$$

Where,

$V_{0}=$ output voltage

$V_{S}=$ supply voltage

$\alpha=$ duty ratio

\subsection{Boost Converter}

It is a step-up converter which increases the voltage at the output side using switch mode power supply. It contains one energy storing element capacitor or inductor. Capacitor used at the input or output side for filter purpose as shown in fig2. To obtain minimum output voltage ripple the capacitor ' $\mathrm{C}$ ' should be sufficiently high. Generally, MOSFET, IGBT, and BJT semiconductors are used as a switch.

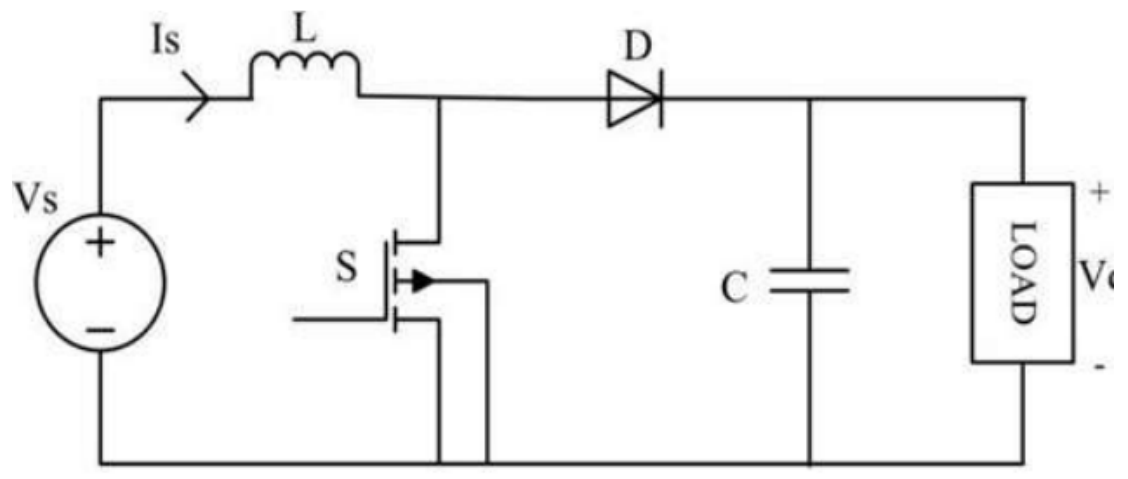

Figure 2.Boost Converter

When Switch S is turned ON, supply current flows through the inductor, switch and back to the source and it charges the inductor L. As the switch become short- circuited, the output gets zero voltage across it. When the switch is OFF, inductor reverses its polarity and discharges through Vs, Inductor L, diode D, load and back to Vs. Current follows above path for the passage due to the effect of supply voltage and inductor L. So ultimately at the output side, we get increased voltage due to the addition of supply voltage and voltage due to inductor action. $[3,4]$ The output equation of this converter is given by,

$$
V 0=V s / 1-\alpha
$$


Where,

vo=output voltage

$V s=$ supply voltage

$\alpha=$ duty ratio

\subsection{Buck Boost Converter}

The non-isolated topology of the buck-boost converter is shown in fig.3.It provides buck or boost voltage at the output side compared to the input side. This converter operates as a bidirectional in which output may be step up or step down voltage as per requirement. This type of bidirectional topology is used for regenerative energy recovery of railway application. This circuit is formed by using one buck and one boost converter. They are connected in series with one another provided that their duty cycle must be the same. It is operated in 3 modes.

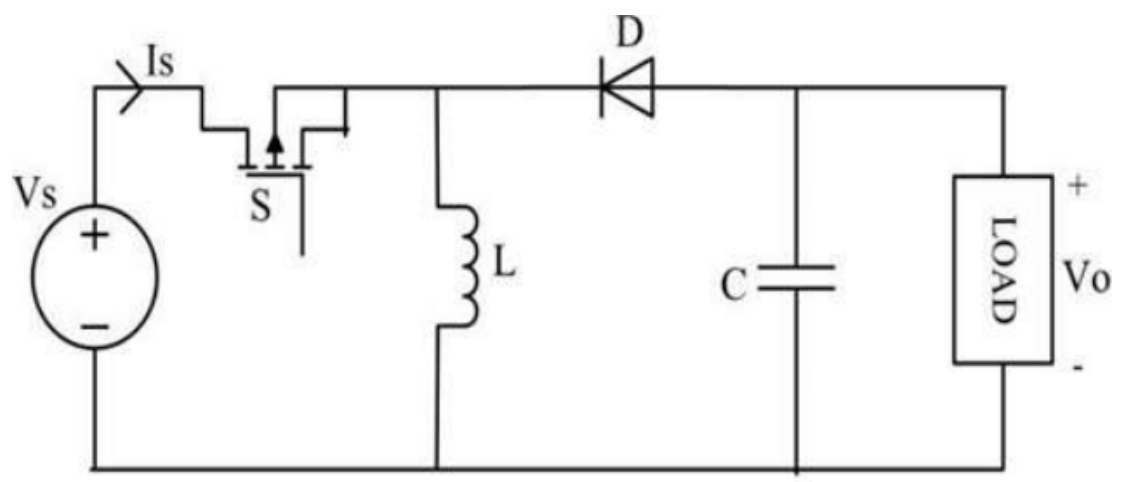

Figure 3.Buck-Boost Converter

In Mode 1, after the switch is ON, supply voltage Vs supplies current which flows through Vs, switch, inductor L and back to voltage source Vs. During this diode D is OFF and the inductor is getting charged and stores energy. The voltage that appears across the inductor is source voltage V. In Mode 2, Switch is OFF; Inductor releases its energy by passing current through $\mathrm{C}$ as well as load resistance. During this period $\mathrm{D}$ is $\mathrm{ON}$ and the Capacitor is charged. The voltage across $\mathrm{R}$ is inductor voltage. Inductor charged the capacitor with a lower plate positive and upper plate negative. And In mode 3, diode D and Switch is OFF. Now capacitor voltage appears across at output which is negative so that its also called inverting regulator. $[3,4]$

\subsection{Sepic Converter}

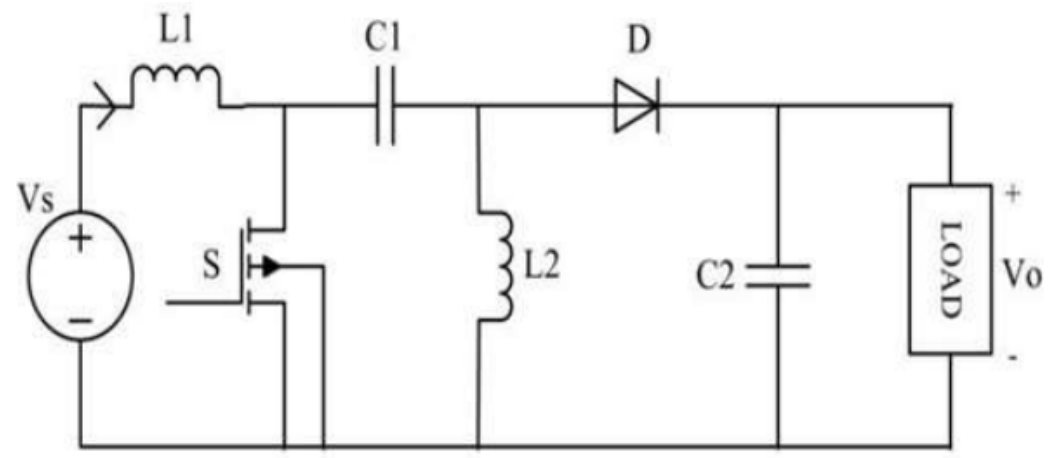

Figure 4. SEPIC converter 
This converter allows its potential output to be step up or step down or similar to its input. Its output control by varying the duty cycle of S1. If the duty cycle is above 0.5 It will step up. And when its duty cycle is below 0.5 It will step down. It is the same as a buck-boost converter. Except that it has the advantage of having output non inverting. When switch $\mathrm{S}$ turns $\mathrm{ON}$ inductor L1 is charged by the input voltage. And L2 is charged by the coupling capacitor.In this case, diode D is OFF. And the output is maintained by $\mathrm{C} 2$. When the switch is OFF, both the output of inductor L1 and inductor L2 charge the capacitor C2 through diode D. Its supply output of lower ripple and provides lower potential stress in capacitor C1 which is superior than the CUK converter. Isolation in input and output easily provided. This type of converter mainly used for the application of higher voltage. The characteristics of this converter are it is a buck and boost voltage easily, non-inverting output, series capacitor, and pulsating output current. $[3,4]$

\subsection{Cuk Converter}

This converter provides a buck or boost voltage at the output side compared to the input side. It is a boost converter followed by a buck converter. The Cuk converter combines the good characteristics of buck and boosts converter in terms of filtering input and output. It has an advantage over the other converter topologies since it enables the low voltage ripple on both input and output sides of the converter. In the fundamental converters topologies, energy is transferred by the inductor whereas in Cuk converter topology energy transfer is depends on the capacitorC1.

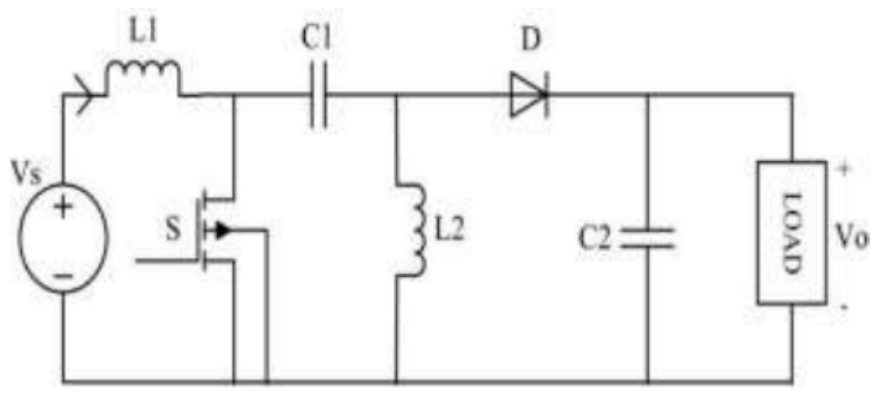

Figure 5.Cuk converter

This converter comprises two inductors, two capacitors, a switch, and a diode as shown in fig5. It is an inverting type converter so that output is negative with respect to the input voltage.[6] Transfer of energy from source to load is done by capacitor $\mathrm{C}$ so that high ripple current in the circuit. The converter has minimum switching losses and provides maximum power at higher efficiency. An inductor is providing at the output side of the converter to improve ripple free characteristics of output current. Output current is flowing through capacitor Co so that the capacitor of high ripple current rating and low value of series resistance are used to reduces the losses.[4,5]

\subsection{Flyback converter}

This converter contains inductor which split into two parts to form the transformer. Basically, we used a ferrite cored high-frequency transformer. Its provide isolation between input and output as shown in fig6. By multiplying turns ratio of the transformer, its provide high voltage configuration. This topology contains magnetizing inductance with turn's ratio N1/N2. Transformer winding has the opposite polarity. MOSFET is used for the switch. When the switch is ON, input Voltage is applied to the primary winding of the transformer. 


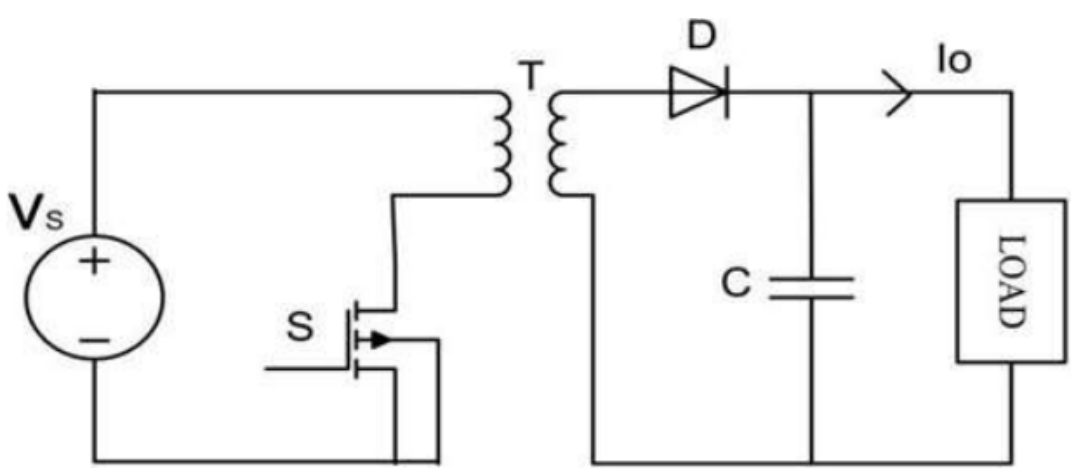

Figure 6. Flyback Converter

Due to the rate of change of magnetic flux, potential stored in it. The reversed biased condition of output diode results in negative potential produced in it. The output capacitor is used to provide energy to the load. When Switch becomes OFF causes current and flux in the primary side reduced and diode in the secondary side operate in forward biased so that positive voltage induces in the secondary side of the transformer. This energy of the transformer is transfer to the load [4]. No requirement of inductor filter and low-cost features make its more popular isolated non-inverting type converter.

\section{COMPARISON OF DC TO DC CONVERTERS}

All the converters which are used in the railway traction system are compared in table no.1 with respect to different features.[3,5]

Table 1 comparison of the DC to DC converters

\begin{tabular}{|c|c|c|c|c|c|}
\hline $\begin{array}{l}\text { CONDERTERS } \\
\text { FEATURES }\end{array}$ & $\begin{array}{l}\text { Buck- } \\
\text { Boost }\end{array}$ & Cuk & $\begin{array}{c}\text { Positive } \\
\text { Buck-Boost }\end{array}$ & SEPIC & Flyback \\
\hline $\begin{array}{l}\text { Output Voltage } \\
\text { Polarity }\end{array}$ & Invert & Invert & Non-invert & Non-invert & $\begin{array}{l}\text { Non- } \\
\text { invert }\end{array}$ \\
\hline Input Current & Pulsating & Nonpulsating & $\begin{array}{l}\text { Depend on } \\
\text { operation } \\
\text { mode }\end{array}$ & Nonpulsating & Pulsating \\
\hline Switch Drive & Floated & Floated & $\begin{array}{l}\text { High with } \\
\text { only one } \\
\text { stage is } \\
\text { active }\end{array}$ & Grounded & Grounded \\
\hline Efficiency & Low & Medium & $\begin{array}{l}\text { High with } \\
\text { only one } \\
\text { stage with } \\
\text { active }\end{array}$ & Medium & Low \\
\hline Cost & $\begin{array}{l}\text { Medium } \\
\text { due to } \\
\text { float drive }\end{array}$ & $\begin{array}{l}\text { Medium due } \\
\text { to additional } \\
\text { block } \\
\text { capacitor }\end{array}$ & $\begin{array}{l}\text { High due to } \\
\text { an additional } \\
\text { switch }\end{array}$ & $\begin{array}{l}\text { Medium due } \\
\text { to additional } \\
\text { block } \\
\text { capacitor }\end{array}$ & $\begin{array}{l}\text { Low due } \\
\text { to } \\
\text { grounded } \\
\text { switch and } \\
\text { no block } \\
\text { capacitor }\end{array}$ \\
\hline
\end{tabular}




\section{APPLICATIONS}

\subsection{For Regenerative Purpose}

In a traction system, a large amount of power is taken from the overhead lines, in order to operate the railway traction. In the traditional method, the regenerative energy is wasted in braking resistor in the form of heat. This power consumption also includes various losses and wastage of energy.

In the last decades or more, there have been relentless efforts made in order to reduce direct power consumption and utilizing the loss energy or breaking energy again for powering management of traction system. Among the various methods, regenerative braking is more efficient. In this case, kinetic energy is converted into electrical energy by the motor which acts as a generator during braking action. In modern methods of regeneration, the bidirectional Dc to DC converter and battery for energy storage are used. Bidirectional Dc to Dc converter is connected between DC feeder and battery energy storage system. In regenerative braking method, the DC to DC converter is used for control the power which is obtained from braking a train. This power is temporarily stored in the battery storage system. By making use of this power, batteries are discharged in order to provide extra power during acceleration of the train. Battery energy storage system is connected to feeder using breaker and feeder is fed from rectifier station as shown in fig6.[8]

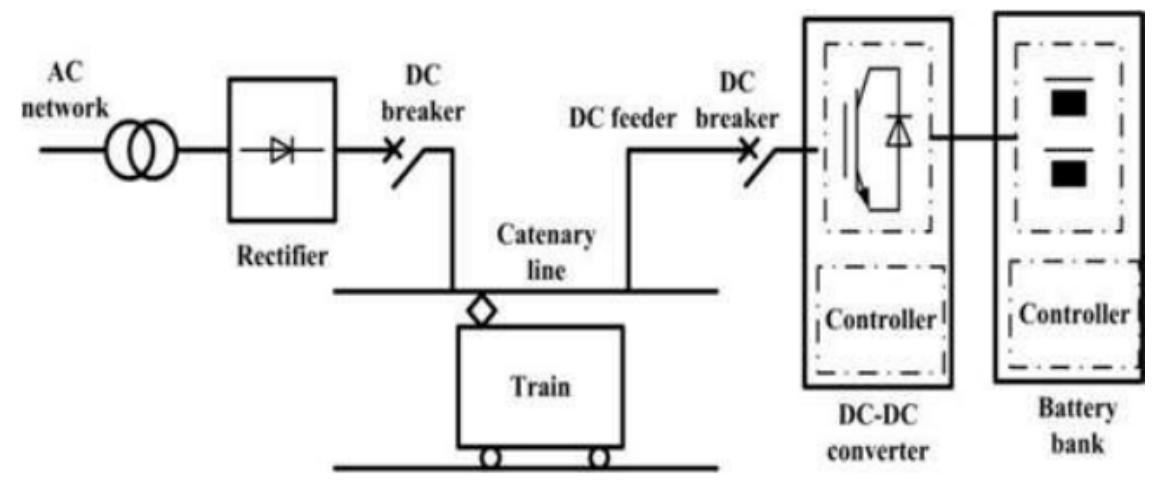

Figure 7 System Configuration Of The Regenerative System

Control characteristic of this system is shown in fig7 DC feeder voltage shows on the Xaxis and power requirement for charging and discharging the feeder current shows on $\mathrm{Y}$ axis[8].

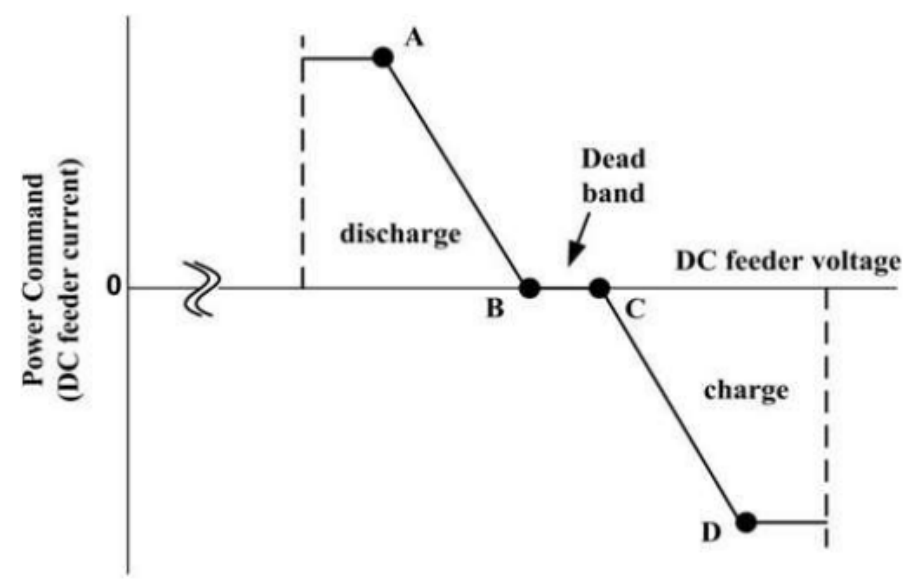

Figure 8. Basic control characteristics 
During the regeneration action of the railway, DC feeder voltage increases. If the voltage increases beyond the dead band upper limit at point $\mathrm{C}$, this system starts charging the battery to increase the voltage from point $\mathrm{C}$ to $\mathrm{D}$ as shown in the figure. In another case when the railway accelerates, due to voltage drop in feeder from rectifier station to the railway, voltage decrease below the dead band point $\mathrm{B}$. and battery discharge with current proportional to the voltage from point $\mathrm{B}$ to $\mathrm{A}$. In this way system provides power to the railway and reimburse the voltage drop. Also when we maintain DC voltage between the pre-described range of values, then the storage system is in standstill state while converter shut down to save energy. In general in traction system, the regenerated energy is 40 to $45 \%$ of motoring power and from this $22 \%$ of energy is used for traction work and The other 22 to $27 \%$ increases the DC feeder voltage.

\subsection{Isolated DC to DC Converter for APU}

Due to increasing demand and technology development, modern traction coaches need continuous electricity supply for auxiliary equipment such as lightning, air conditioner, battery charging, indication lamp, pump, and passenger information system, etc.[10] So that the auxiliary converter unit is required to generate these types of voltage to serves these auxiliary loads of railway traction. In order to obtained require amount of supply voltage, an auxiliary power unit is needed which easily convert overhead line voltage into require level of the equipment supply voltage. Generally, 24V supply is needed for battery charger and $400 \mathrm{ac}$ is for three-phase consumers. Supply voltage frequency may be $50 \mathrm{HZ}$ or variable as per equipment requirement.

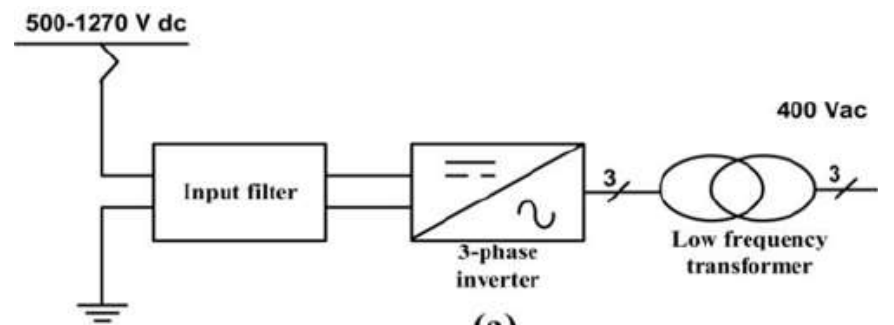

(a)

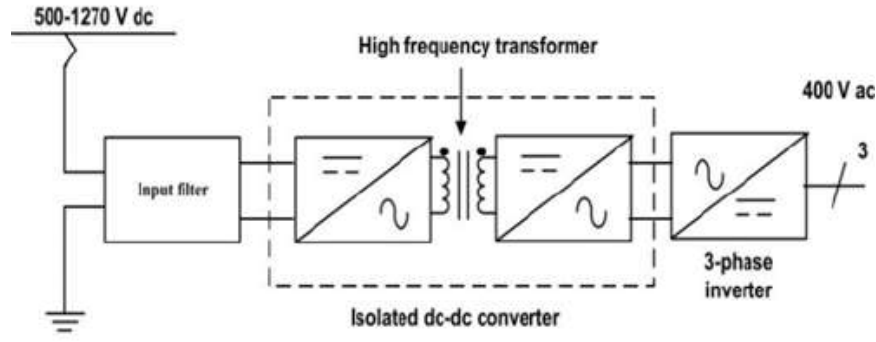

(b)

Figure 9. Simplified schematic of an APU. (a) Conventional APU. (b) Proposed APU

In the conventional method, electrical isolation between overhead line voltage $3 \mathrm{KV}$ dc and auxiliary power supply equipment of each port is realized by lower frequency transformer as shown in fig8 a. which is very large and bulky causes increase the weight of the APU. In order to minimize weight and size of the APU, the new power unit is used that consists of isolated DC to DC converter as shown in the figure, due to the addition of proposed system into the circuit, elimination of high weight and low frequency transformer is achieved.[9]

\section{CONCLUSIONS}

This paper overview the different types of DC to DC converter and its application for railway traction system. Depending on operation of converter, cost and its output, these are used in 
traction application. From the application point of view Bidirectional DC to DC converter preferably used in railway traction. Its operation in the regenerative system makes its more efficient to power management for the railway system. Also use of isolated DC-DC converter in auxiliary power unit makes the railway traction system lightweight, high acceleration capacity and continuity of electrical supply for auxiliary equipment.

\section{REFERENCES}

[1] Dr Roger D White, "Dc Electrification Supply System Design", 6th IET Professional Development Course on Railway Electrification Infrastructure and Systems (REIS2013).

[2] Jency Joseph, JL Juliha and Josh F, "Review on the Recent Development of the Power Converters for Electric Vehicle", Proceedings of the 2nd International Conference on Communication and Electronics Systems (ICCES 2017) IEEE XploreCompliant

[3] Gaurav Gupta, Dr. Prerna on "Comparative Study of Various DC-DC Converters used in AI-Based Solar fed PMBLDC Motor Drive”, in IEEE INDICON 2015, 978-1-4673- 65406/15, 2015IEEE.

[4] Mangesh A. Chewale, RiteshA.Wanjari, VirajB.Savakhandeand Pravin R.Sonawane,"A Review on Isolated and Non-isolated DC-DC Converter for PV Application", International Conference on Control, Power, Communication and Computing Technologies,Dec2018

[5] Reshma M S, Midhun Basil Alias, Haritha S Nair and Priya Jose, "Cuk Converter Fed Electric Vehicles", National Conference on "Emerging Research Trends in Electrical, Electronics \& Instrumentation, 2017

[6] Devi, M. Latha, and M. Chilambarasan. "Design and simulation of incremental conductance MPPT using self liftcuk converter", 2013 International Conference on Renewable Energy and Sustainable Energy (ICRESE),2013

[7] H. Suryoatmojoet al., "Comparisons of Cuk, SEPIC and Zeta converter performance for harmonics mitigation and PFC in BLDC speed control," 2016 International Seminar on Intelligent Technology and Its Applications (ISITIA), Lombok, 2016, pp.681-686.

[8] Z. Li1, S. Hoshina1, N. Satake2, and M. Nogi2, "Development of DC/DC Converter for Battery Energy Storage Supporting Railway DC Feeder Systems", EEE Transactions on Industry Applications, Dec2016

[9] Nico H. Baars, Jordi Everts,, HenkHuisman, Jorge L. Duarte and Elena A. Lomonova, “A 80-kW Isolated DC-DC Converter for Railway Applications", IEEE transactions on power electronics, vol. 30, no. 12, pp. 6639-6647, Dec2015.

[10] Olivier Deblecker, Adriano Moretti, and François Vallée , "Comparative Study of SoftSwitched Isolated DC-DC Converters for Auxiliary Railway Supply", IEEE transactions on power electronics, vol. 23, no. 5, september2008

[11] A. Lachichi, “ DC/DC Converters for High Power Application:A Survey”, 3rd International Conference on Electric Power and Energy Conversion Systems, oct.2013 